\title{
Randomized, Double-blind, Placebo Controlled Phase III Trial of Oxymetholone for the Treatment of HIV Wasting and Lipodystrophy
}

Priyo Sasongko*‡

\author{
Address: Goverment of Indonesia, Jakarta, Indonesia \\ Email: Priyo Sasongko* - prio_sigit@yahoo.com \\ * Corresponding author ‡Presenting author
}

\author{
from 2005 International Meeting of The Institute of Human Virology \\ Baltimore, USA, 29 August - 2 September 2005 \\ Published: 8 December 2005 \\ Retrovirology 2005, 2(SuppI I):P86 doi:10.1 I86/1742-4690-2-SI-P86
}

\section{Purpose of the Study}

Although HAART has greatly impacted treatment of HIV infection, lipodystrophy and HIV wasting still represent unsolved problems in HIV therapy and patient care. Oxymetholone, a testosterone derivative, has been shown to promote weight gain in AIDS-associated wasting.

\section{Methods}

We analyzed the effects of oxymetholone [50 mg BII) and TII)] in a randomized (1:1:1), double-blind, placebo-controlled phase III study with 92 subjects (all on ART) experiencing unintended weight loss $>10 \%$ of ideal weight according to Broca with special emphasis on body composition measurement 80 patients (69 men, 11 women, mean age:38,8 years) completed the 16-week doubleblind study phase.

\section{Results}

Mean weight gain was $+3.7 \pm 3.5 \mathrm{~kg}$ and $+3.1 \pm 2.7 \mathrm{~kg}$ in the oxymetholone groups [BII); $\mathrm{n}=25 \mathrm{vs} \mathrm{TII}$ ); $\mathrm{n}=27$ ] as opposed to $+0.97 \pm 3.4 \mathrm{~kg}$ in the placebo were observed in body cell mass (30.6 before vs 32.5 after therapy), lean body mass $[56.3$ before vs 59.0 after therapy in the BII) groupl and body mass index (21.4 before vs 22.1 after therapy) exclusively in oxymetholone-treated patients. The extracellular mass to body cell mass ratio, $(\mathrm{p}<$ $0,0001)$. Total body fat was unchanged by oxymetholone treatment. Adverse events were mainly hepatic occurring in $14 \%$ of oxymetholone-treated patients with significant elevations of AST, ALT and GGT;2 patients (7.4\%) in the BII) arm experienced grade 3 and 4 liver toxicity compared with $6[21.4 \%)$ in the TII] arm.

\section{Conclusion}

Oxymetholone was found to have true anabolic effects in a double-blind, placebo-controlled phase III trial. The (BII) $(100 \mathrm{mg} / \mathrm{d})$ regimen appeared equally effective to TII) $(150 \mathrm{mg} / \mathrm{d})$ dosing while displaying reduce liver toxicity. Due to its favourable protein anabolism, it may be recommended for therapy of wasting and lipodystrophy I HIV-infected subjects. 